\title{
Systematic Analysis on Key Success Factors and Strategic Planning of Green Ship Development
}

\author{
Ching-Kuei Kao, Qi-Qi Chen, Yang Zhong, and Peng-Jung Lin
}

\section{ABSTRACT}

In today's era of advocating green and low carbon, the development of green ships based on new technologies and new energy can improve the status of China's shipping enterprises in the world. Specifically, such development is of great significance to marine environmental protection and can promote the sustainable development of China's economy. By referring to relevant literature on green ships, this study summarizes 20 development indicators of green ships as the basis for the questionnaire design. On the basis of the data collected from the questionnaire, the grey relational analysis method is used to extract six key development indicators of green ships. TRIZ analysis is also adopted to establish innovative improvement strategies for each key indicator. Subsequently, the short-, medium-, and long-term development planning of these strategies are summarized according to the order of strategic development. Such strategies are also divided into three development directions according to their content: intelligent systems, incentive systems, and green devices. Therefore, the strategic planning of this study can provide a clear guide for shipping enterprises to develop green ships and allocate resources according to the key indicators of green ships under limited resources, which can serve as the foundation for achieving further successful development in the fiercely competitive domestic and international markets.

Keywords: green ship, key success factor, strategic planning.
Submitted : February 8, 2020

Published : February 18, 2021

ISSN: 2507-1076

DOI: $10.24018 /$ ejbmr.2021.6.1.743

Ching-Kuei Kao*

Key Laboratory of LNG Industry Chain, Fujian University of Technology, China. (e-mail: ckkao@fjut.edu.cn)

Qi-Qi Chen

Department of logistics management,

Beijing Institute of Technology, Zhuhai, China.

(e-mail: 995866881@qq.com)

Yang Zhong

Department of logistics management,

Beijing Institute of Technology, Zhuhai,

China.

(e-mail: zhongyang_jLu@163.com)

Peng-Jung Lin

Department of Business Administration,

Fujian University of Technology, China.

(e-mail: linpengjung@qq.com)

*Corresponding Author

\section{INTRODUCTION}

Due to the large cargo carrying capacity, low shipping cost, wide route network coverage, and high demand, ocean transportation has become the most important mode of transportation in international logistics. The development of China's economy brings opportunities for that of its shipping enterprises. Approximately $90 \%$ of China's total import and export cargo are transported by sea, accounting for a large proportion of the world's maritime competition [1]. The container throughput has been ranked first in the world for many years; the number of fleets is third in the world; and among the top 10 container ports, seven are in China [2]. The rapid development of marine transportation has also brought about significant pollution to the marine environment. According to the "2018 China Motor Vehicle Environmental Management Annual Report," ships should strictly implement the current international conventions and domestic laws and regulations regarding the emission control requirements of sulfur oxides, particulate matter, and nitrogen oxides. From January 1, 2019, when ships enter the area of emission control, fuel oil with a sulfur content of less than $0.5 \% \mathrm{~m} / \mathrm{m}$ must be used [3]. Under strict laws and regulations, China's shipping enterprises should thus develop green ships in the low-carbon era as an important bargaining chip for competition.

According to the Energy Efficiency Design Index (EEDI) developed by the International Maritime Organization (IMO) to reduce carbon dioxide emissions from ships, the carbon efficiency of ships must be increased by $10 \%$ for ships built between 2015 and 2019 and by $20 \%$ for ships built between 2021 and 2024 [4]. For the development of China's shipping enterprises, shipping enterprises must therefore conduct technological innovations to develop green ships to meet the requirements of EEDI and gain a foothold in the fierce shipping market.

The development of green ships is also of great significance in terms of social and economic benefits. First, in terms of social benefits, the development of green ships is based on sustainable development to achieve energy conservation and emission reduction and uses renewable resources as clean fuels to reduce ships' pollution to the atmosphere and sea. Second, in terms of economic benefits, the development of green ships is conducive to the use of low-cost clean fuel oil and government subsidies, conducive to opening up an international reputation among international shipping enterprises. Such usage can help shipping enterprises apply for green certification and increase their market share in international shipping.

However, the development of green ships must meet the requirements of green ship indicators, which at present, have three main categories: design and manufacturing, operation, and environment. Many detailed indicators are under each category. Rockart [5] stated that any enterprise has certain 
key areas. If these key areas are strengthened and implemented, then the enterprise can enhance its competitive advantage and exhibit a successful performance. Such key areas are the key success factors (KSFs). Therefore, KSFs refer to the fact that the enterprise has achieved favorable results in some key activity areas, which play a key role in achieving its goals [6]. Aaker [7] clearly pointed out that KSFs are the most important competitive ability or asset that enterprises must have in market competition. Successful companies generally have a certain degree of KSFs and have advantages in these factors; on the contrary, failed companies lack one or several KSFs. Only by grasping KSFs can companies build a lasting competitive advantage. Consequently, investing resources on important and key green ship indicators with limited resources to increase the chances of successfully developing green ships is an important decision for shipping enterprises. Therefore, this study investigates the KSFs and strategies for the development of green ships. The problem that shipping enterprises can allocate resources on the basis of the KSFs of green ships under the condition of limited resources and can improve the chances of developing green ships is also addressed.

\section{LITERATURE REVIEW}

This section comprises two parts: the concept of green ships and the green ship indicators.

\section{A. Concept of Green Ships}

Green ships are designed with the core concepts of lowcarbon environmental protection and maximum utilization of limited resources. Such concepts can be defined as the entire process from ship design to dismantling and recycling that meets the requirements of the green environment and achieves sustainable economic and environmental development; ships that can realize resource recycling are also involved [8]. Green ships must embody the basic principles of energy saving and consumption reduction and environmental pollution reduction throughout their life cycle. The greenness of ship manufacturing and operation processes must also be improved. From the design stage, green awareness should be established to design green ships with excellent design performance and prevent pollution problems from further harming the environment.

\section{B. Indicators of Green Ship}

Twelve, six, and two indicators of green ships have been sorted out on the basis of the literature for design and manufacturing, for operation, and for the environment; the definitions of the indicators are listed in Tables 1, 2, and 3, respectively.

\section{QUESTIONNAIRE DESIGN AND DATA ANALYSIS}

This section has two parts: the design of the questionnaire on the importance of green ship indicators and the data analysis based on the data collected from the questionnaire.

\section{A. Questionnaire Design}

The questionnaire was designed according to the indicators in Tables 1-3. The questionnaires were filled out by relevant ship operators and scholars who were selected through snowball sampling. The five-point Likert scale was used, which was divided into "very important" (five points), "comparatively important" (four points), "general" (three points), "less important" (two points), and "very unimportant" (one point). The uniform resource locator of the questionnaire was https://www.wjx.cn/pq/24496003.aspx?t

$=636917385754565500$, and 21 valid questionnaires were returned.

\section{B. Data Analysis}

Based on the recovered 21 valid questionnaires, the grey relational analysis was conducted to extract the important key factors of green ships. Subsequently, TRIZ was used to formulate development strategies for these factors.

\section{Grey relational analysis}

First, the comparison sequence and the reference sequence are determined. Second, the grey relational coefficient and grey relational degree of the 20 green ship indicators are calculated. Last, the grey relational degree is sorted from large to small to obtain the grey relational sequence as the basis for selecting the key green indicators of ships. The detailed steps are as follows [29]:

Step 1. In this study, the five-point Likert scale is used, assuming that the comparison sequence is $x_{i}=$ $\left\{x_{i}(1), x_{i}(2), \ldots, x_{i}(k)\right\}$, where $x_{i}(k)$ is the answer score of the $i^{\text {th }}$ respondent to the $k^{\text {th }}$ green ship indicator item in the questionnaire, and the reference sequence is $x_{0}=\left\{x_{0}(1), x_{0}(2), \ldots, x_{0}(k)\right\}$. Considering that five points indicate that the question item of the green ship index has the highest degree of importance, $x_{0}(1)=x_{0}(2)=\ldots=$ $x_{0}(k)=5$. The value of the difference sequence is defined as the absolute difference between the comparison sequence and the reference sequence, expressed as $\Delta_{0 i}(k)=\left|x_{0}(k)-x_{i}(k)\right|$.

Step 2. The grey relational coefficient $\left(r\left(x_{0}(k), x_{i}(k)\right)\right)$ is shown in Equation (1) in which the identification coefficient $(\zeta)$ takes its average value 0.5 , and $\Delta \min$ and $\Delta \max$ are respectively expressed as the minimum and maximum of the difference sequence value of the $k^{\text {th }}$ green ship indicator item in the questionnaire. When the grey relational coefficient approaches 1 , it means that the reference sequence is closely related to the comparison sequence. Otherwise, the correlation degree between the two is low.

Step 3. The grey relational degree $\left(r\left(x_{0}, x_{i}\right)\right)$ is presented in Equation (2), which is the average value of the grey relational coefficient and represents the degree of correlation between the comparison sequence and the reference sequence. The greater the grey relational degree, the greater the importance of the item in the questionnaire.

Step 4. The grey relational sequence can be obtained by sorting the value of the grey relational degree from largest to smallest, which is the key basis for decision making. 
TABLE 1: DESIGN AND MANUFACTURING INDICATORS OF GREEN SHIPS

\begin{tabular}{|c|c|c|}
\hline Indicator & Definition & Source \\
\hline $\begin{array}{l}\text { 1. Ship form } \\
\text { optimization }(\mathrm{Q} 1)\end{array}$ & $\begin{array}{l}\text { The main dimensions of ships, the hull shape, and the shape of the bow and stern are optimized. Through these } \\
\text { measures, the hull resistance is reduced to achieve the purpose of improving energy efficiency. }\end{array}$ & [9] \\
\hline $\begin{array}{l}\text { 2. Ships without } \\
\text { ballast water }(\mathrm{Q} 2)\end{array}$ & $\begin{array}{l}\text { Those that need only a small amount or no ballast water under normal operating conditions, thus reducing pollution } \\
\text { treatment costs. }\end{array}$ & [10] \\
\hline $\begin{array}{l}\text { 3. Green processing } \\
\text { technology }(\mathrm{Q} 3)\end{array}$ & $\begin{array}{l}\text { It mainly includes net shape manufacturing, dry processing, simulation technology, network technology and virtual } \\
\text { reality technology, and agile manufacturing to achieve the purpose of reducing raw materials and energy } \\
\text { consumption. }\end{array}$ & [11] \\
\hline $\begin{array}{l}\text { 4. Green welding } \\
\text { technology (Q4) }\end{array}$ & $\begin{array}{l}\text { It is mainly reflected in the use of energy-saving welding machines by ship enterprises and the use of high-efficiency, } \\
\text { arc-free, and dust-free welding materials and methods. }\end{array}$ & {$[12]$} \\
\hline $\begin{array}{l}\text { 5. Green coating } \\
\text { process (Q5) }\end{array}$ & $\begin{array}{l}\text { Through the application of environmentally friendly coating technology and coating facilities, the purpose of } \\
\text { improving the quality of ship coating and operating efficiency can be achieved to reduce resource consumption. } \\
\text { Hazardous emissions can also be gained. }\end{array}$ & [13] \\
\hline $\begin{array}{l}\text { 6. Ship parallel } \\
\text { collaborative design } \\
\text { technology (Q6) }\end{array}$ & $\begin{array}{l}\text { It refers to the coordinated planning and design of ships, manufacturing, operation, and dismantling and recycling } \\
\text { stages to shorten the ship design cycle and increase the service life of ships. }\end{array}$ & $\begin{array}{l}{[10]} \\
{[14]}\end{array}$ \\
\hline $\begin{array}{l}\text { 7. Ship weight } \\
\text { reduction (Q7) }\end{array}$ & $\begin{array}{l}\text { Lightweight methods from the perspectives of materials, manufacturing processes, and structural optimization } \\
\text { designs to reduce the weight of ships. }\end{array}$ & $\begin{array}{l}{[10]} \\
{[15]}\end{array}$ \\
\hline $\begin{array}{l}\text { 8. Ship noise control } \\
\text { (Q8) }\end{array}$ & $\begin{array}{l}\text { Ship noise mainly comes from the engine room, ventilation system, deck machinery, steering gear, and propulsion } \\
\text { system of ships. Corresponding technical measures should be taken to control the occurrence, transmission, and } \\
\text { reception of ship noise sources. }\end{array}$ & $\begin{array}{l}{[11]} \\
{[15]}\end{array}$ \\
\hline $\begin{array}{l}\text { 9. Ship powerplant } \\
\text { (Q9) }\end{array}$ & The general term for ship propulsion and other power equipment that must provide various energy sources. & [16] \\
\hline $\begin{array}{l}\text { 10. Recyclable design } \\
\text { (Q10) }\end{array}$ & $\begin{array}{l}\text { To save materials and reduce wastes, full consideration should be given to the possibility of recycling the various } \\
\text { materials of ships and the methods of recycling at the stage of ship design. }\end{array}$ & [17] \\
\hline $\begin{array}{l}\text { 11. Standardized } \\
\text { design }(\mathrm{Q} 11)\end{array}$ & Design one or more standardized series of products for different types of green ships to reduce waste of resources. & [13] \\
\hline $\begin{array}{l}\text { 12. Ship drag } \\
\text { reduction technology } \\
\text { (Q12) }\end{array}$ & $\begin{array}{l}\text { The basic resistance of moving objects in the fluid is composed of frictional resistance, viscous pressure resistance, } \\
\text { and wave-making resistance. Reducing the frictional resistance of ships can effectively reduce fuel consumption and } \\
\text { improve the economy of ship operations. }\end{array}$ & [18] \\
\hline
\end{tabular}

TABLE 2: OPERATION INDICATORS OF GREEN SHIPS

\begin{tabular}{|c|c|c|}
\hline Indicator & Definition & Source \\
\hline $\begin{array}{l}\text { 1. Energy saving and emission } \\
\text { reduction }(\mathrm{Q} 13)\end{array}$ & $\begin{array}{l}\text { The use of appropriate technologies, rational use of resources to reduce ship energy consumption, pollutant } \\
\text { emissions, losses, and wastes. }\end{array}$ & $\begin{array}{l}19] \\
{[20]}\end{array}$ \\
\hline $\begin{array}{l}\text { 2. Ship energy consumption } \\
\text { detection system (Q14) }\end{array}$ & $\begin{array}{l}\text { The use of the energy consumption online detection system of ships to record their fuel consumption and } \\
\text { other related data in real time for achieving refined energy management. }\end{array}$ & $\begin{array}{l}{[21]} \\
{[22]}\end{array}$ \\
\hline $\begin{array}{l}\text { 3. Ship operation optimization } \\
\text { (Q15) }\end{array}$ & $\begin{array}{l}\text { The comprehensive consideration of ship equipment, management, operation, and other aspects to } \\
\text { optimize the capacity structure and improve ship energy efficiency management. }\end{array}$ & $\begin{array}{l}{[23]} \\
{[24]}\end{array}$ \\
\hline $\begin{array}{l}\text { 4. International regulations and } \\
\text { policies (Q16) }\end{array}$ & $\begin{array}{l}\text { In accordance with the requirements of the IMO regulations for ship sulfur emission restrictions, after } \\
\text { January } 1,2020 \text {, ships entering the emission control area should use fuel oil with a sulfur content of } \leq \\
0.5 \% \mathrm{~m} / \mathrm{m} \text {. Therefore, shipping companies must adopt appropriate plans to reduce ship sulfur emissions. }\end{array}$ & [25] \\
\hline $\begin{array}{l}\text { 5. Sewage treatment technology } \\
\text { improvement (Q17) }\end{array}$ & $\begin{array}{l}\text { It refers to the sewage generated from ships, including ship domestic sewage (black water), grey water, and } \\
\text { ship oil sewage, which should be purified through high-tech technology. }\end{array}$ & [26] \\
\hline $\begin{array}{l}\text { 6. Waste recycling and utilization } \\
\text { (Q18) }\end{array}$ & $\begin{array}{l}\text { The process of turning ship waste into treasure and protecting the ecological balance. Hazardous ship } \\
\text { waste must be disposed of by an external unit with a hazardous waste business license to avoid harming } \\
\text { the environment. }\end{array}$ & [27] \\
\hline
\end{tabular}

TABLE 3: ENVIRONMENT INDICATORS OF GREEN SHIPS

\begin{tabular}{|c|c|c|}
\hline Indicator & Definition & Source \\
\hline 1. Harmless ship dismantling & The dismantling process of ships should be planned before the actual dismantling, and all hazardous & [23] \\
\hline$(\mathrm{Q} 19)$ & materials and wastes after the dismantling should be treated in an environmentally sound manner. & [27] \\
\hline 2. Renewable energy (Q20) & $\begin{array}{l}\text { Renewable energy is harmless or minimally harmful to the environment. Using solar energy and wind } \\
\text { energy can help ships achieve energy-saving and emission reduction effects during operation. }\end{array}$ & [28] \\
\hline
\end{tabular}

$$
\begin{aligned}
& r\left(x_{0}(k), x_{i}(k)\right)=\frac{\Delta \min +\zeta \Delta \max }{\Delta_{0 i}(k)+\zeta \Delta \max } \\
& r\left(x_{0}, x_{i}\right)=\frac{1}{n} \sum_{k=1}^{n} r\left(x_{0}(k), x_{i}(k)\right)
\end{aligned}
$$

Then, the calculation values of the grey relational degree are grouped using K-Means clustering. The 20 green indicators of ships are divided into nine groups, and the results are shown in Fig. 1. Regarding the extraction of the number of KSFs, Daniel [30] believed that three to six key factors affect the success of a company. If the company lacks these key factors, then its operation will easily fail. Therefore, the KSFs of green ship development are selected according to this principle. Figure 1 presents that six KSFs are selected to meet the Daniel principle, namely, the "Standardized design" (Q11) and "Ship parallel collaborative design technology" (Q6) from the first group, "Ship powerplant" (Q9) and "Ship operation optimization" (Q15) from the second group, and "Ship energy consumption detection system" (Q14) and "Energy saving and emission reduction" (Q13) from the third group. 


\section{Analysis of TRIZ}

TRIZ analysis means applying the contradiction matrix and 40 innovation principles [31] to propose innovative improvement countermeasures. The analysis steps are: (1) description of the problem, (2) definitions of the improving and worsening parameters, (3) identification of the intentions of the innovative principles from the contradiction matrix, and (4) formulation of strategies according to innovative principles [32]. The TRIZ analysis results of the six key indicators are explained below.

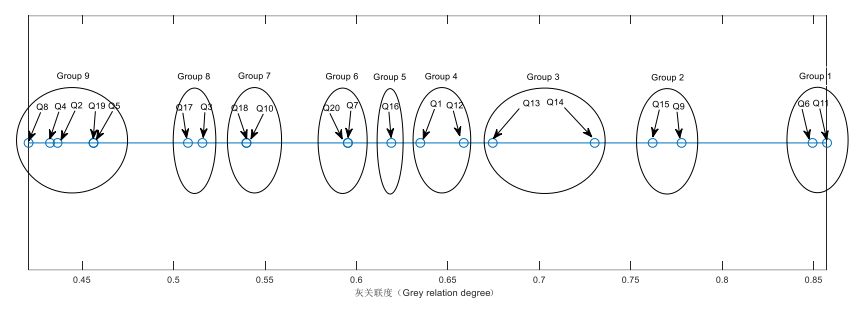

Fig. 1. Line graph of grey relational degree of green ship indicators.

1) Standardized design (Q11)

(1) Description of the problem: At present, a single duplication exists in the design of ship types in China, and the purposes and types of ships are similar. The method of ship design is neither conducive to the collection, classification, and arrangement of ship design drawings and data nor to the subsequent research and development (R\&D) of new ship products. Due to the professional design of ship products, the wide scope, and the long design cycle, a single repeated design obviously cannot keep up with the rapid changes in the market. To avoid wasting human, financial, and material resources caused by repeated design, designing these ship products into one or more series is necessary to facilitate shipbuilding enterprises and thus improve shipbuilding quality and efficiency.

(2) Definition of the improving and worsening parameters: According to the problem definition, China's shipbuilding industry lacks a standardized series of ship products. To avoid the repetition of ship products with similar design uses and types, extensive investigations, studies, summarizations, and sorting of ship types and ship products can be conducted as reference materials for designing standardized series of products. Therefore, corresponding to 39 engineering parameters [31], the improving parameter is " 32 : manufacturability." However, the extensive collection of ship drawings and materials requires additional investigation costs. Thus, the worsening parameter is "19: energy spent by moving object."

(3) Identification of the intentions of the innovative principles from the contradiction matrix: According to the selected improving and worsening parameters, the innovation principles corresponding to the contradiction matrix are "Principle 28: Mechanics substitution," "Principle 26: Copying," and "Principle 30: Flexible shells and thin films." The appropriate innovation principle is chosen according to the intention of the innovation principle as "Principle 26: Copying."

(4) Formulation of strategies according to innovative principles: "Principle 26: Copying" is defined as the use of simple and cheap replicas for expensive and fragile objects or the replacement of an object or program with an optical copy. Therefore, the proposed strategy (S1) is to use electronic databases to collect and store the information of ship design and to apply rapid prototyping manufacturing for standardized ship design. First, conducting an extensive investigation and research on ship information nationwide or globally is necessary; summarizing and organizing the entire set of ship drawing information collected through an electronic database is also important [33]. Second, according to the collected ship information, $R \& D$ and design capabilities and the green ship types that must be developed should be combined to select the best type and then perfect the design. In this way, one or more standardized series of products can be designed for different types of green ships. Last, rapid prototyping manufacturing can be performed to convert the key and complex components of green ships into a solid model; then, its manufacturability and assembly design are tested and modified. Thus, the quality of the standard series of marine products is continuously improved to reduce the waste of resources and shorten the ship development and manufacturing cycle.

2) Ship parallel collaborative design technology (Q6)

(1) Description of the problem: Given that the ship design process involves a large number of people in different units and departments, a huge number of design documents and design drawings are generated. The data sources come from different design departments, and each design unit is relatively independent and cannot realize real-time information sharing, resulting in poor coordination among design departments; a large amount of design rework; and low efficiency of information storage, search, and application. Therefore, implementing effective tracking and control management for the parallel collaborative design of ships during the execution of the ship project is difficult.

(2) Definition of the improving and worsening parameters: According to the definition of the problem, each design department performs tasks separately in the ship design process, leading to problems that cannot be communicated and coordinated in time, thereby reducing the speed and efficiency of ship $R \& D$ and design. Therefore, establishing a management system or feedback mechanism is necessary, so that all departments and personnel involved in ship design can increase teamwork and collaborative operation and improve work coordination. Hence, the improving parameter is "35: adaptability." However, the development of a parallel collaborative management system or feedback mechanism can enable various design departments to participate in and follow up ship design at various stages at the same time, which can further impose high requirements on the coordination and integration of various design departments. Thus, the worsening parameter is " 36 : Complexity of device."

(3) Identification of the intentions of the innovative principles from the contradiction matrix: The innovation principles corresponding to the contradiction matrix are "Principle 29: Pneumatics and hydraulics," 
"Principle 15: Dynamics," "Principle 28: Mechanics substitution," and "Principle 37: Thermal expansion." Specifically, the appropriate innovation principle is "Principle 15: Dynamics."

(4) Formulation of strategies according to innovative principles: "Principle 15: Dynamics" is defined as moving or adapting a rigid and inelastic object to break it down into interactive sub-parts and can dynamically adjust to the final operating conditions according to the external environment or process. Therefore, the proposed strategy (S2) is to establish an information technology (IT) service management system to optimize the parallel collaborative design process of ships. Such a process is a series of mutually parallel collaborative design-related activities that jointly create value for customers. To effectively track and control the parallel collaborative design process of ships and improve the operational efficiency of the process, the following measures can be taken. First, the process re-engineering of the parallel collaborative design of ships can be implemented according to customer needs. For ship types with completed standardized designs, the relevant design department can discuss the cancellation or merger of the design process. Subsequently, the design process is reordered according to a reasonable design logic to make the design work more organized and work more efficiently than before. Second, considering that the management of the ship design process is complicated and related to multiple departments, an IT service management system is needed to assist in the management, tracking, and continuous improvement and to integrate and share resources. Before the start of the specific design work, the managers of each design department should coordinate the work according to the design schedule requirements and achieve unified data management through the IT service management system. The information data completed by each design department must be uploaded as scheduled according to the schedule of the design process, so that the managers of each design department can track and monitor the automatically archived documents through the IT service management system. If managers have any questions, then they can promptly provide feedback in the IT service management system and coordinate and solve the questions in time, breaking the previous situation of independent work in each design stage and effectively shortening the ship design cycle [34].

3) Ship powerplant (Q9)

(1) Description of the problem: The source of pollution from ships mainly comes from ship powerplants. Most domestic ships in China use diesel engine powerplants because they have a wide range of power and can meet the requirements of different ship types. With the global oil depletion, the excessive use of oil and coal as fuels can aggravate the energy crisis and environmental degradation. In addition, the structure and working principle of the diesel engine determine that its vibration and noise problems are difficult to solve, thereby affecting the daily work quality and life of crew members. If such things continuously occur, then the crew members' hearing can be severely damaged. Due to the severe pollution of the marine environment and strict sulfur-limiting policies and regulations that place high requirements on the performance of ship powerplants, China's shipbuilding industry should devote itself to the R\&D of green ship powerplants to minimize energy consumption and exhaust emissions while ensuring the normal speed of ships.

(2) Definition of the improving and worsening parameters: The pollutants emitted by ships mainly come from the insufficient energy saving of their powerplants, resulting in the continuous pollution of the marine environment. Consequently, developing a new type of green ship powerplant is necessary to reduce fuel consumption and power while ensuring normal speed for realizing the energy saving of green ships. Thus, the improving parameter is " 21 : Power." However, the R\&D of new green ship powerplant technology requires extended financial support. Therefore, the worsening parameter is "19: energy spent by moving object."

(3) Identification of the intentions of the innovative principles from the contradiction matrix: Based on the selected improving and worsening parameters, the innovation principles corresponding to the contradiction matrix are "Principle 6: Universality," "Principle 19: Periodic action," "Principle 37: Thermal expansion," and "Principle 18: Mechanical vibration." Specifically, the appropriate innovation principle is "Principle 6: Universality."

(4) Formulation of strategies according to innovative principles: "Principle 6: Universality" is defined as enabling an object or structure to perform multiple functions, that is, cross-domain training and diverse equipment. Therefore, the proposed strategy (S3) is to develop a new type of high-efficiency and energysaving green ship powerplant equipment. The following measures can be considered. First, a new type of ship propulsion device can be used, such as a diesel-electric hybrid powerplant, which can be used as an engine or as a motor. When a ship is sailing at a constant speed, the main propulsion diesel engine driveshaft is used to drive the generator to provide the electrical energy required for the daily operation of the ship to reduce the power and fuel consumption rate and achieve the purpose of energy-saving. When the ship needs to sail at a low speed or the main engine fails, the electric power provided by the ship's power generation group is used to realize electric propulsion to meet the specific ship operation requirements [35]. Second, clean energy can be used, such as new energy solar energy, wind energy, and fuel cell, to replace petroleum as fuel; such replacement can achieve the ideal effect of a green ship with low noise and low pollution.

4) Ship operation optimization (Q15)

(1) Description of the problem: During the actual operation of a ship, the effective energy efficiency management implemented by shipping enterprises can optimize the speed, reduce the fuel consumption of the ship, fuel cost, and emission to realize the optimization of the ship traveling and achieve a balance between environmental and economic benefits. However, shipping enterprises in China lack relevant training and publicity for their 
crew members in terms of energy efficiency management. Moreover, the actual work guidance is inaccurate and fails to achieve the expected results. Thus, the frontline crew members on board do not understand the actual management operations and fail to implement the energy efficiency management plan during operation. Furthermore, the energy efficiency management plan for ship operations only focuses on fuel costs and ignores energy efficiency and the overall operating costs of companies, thereby hindering shipping enterprises from transforming and upgrading to develop green ships.

(2) Definition of the improving and worsening parameters: China's shipbuilding enterprises must provide relevant energy efficiency management training to their crew members, so that they are fully familiar with the content regulations and implementation requirements of ship energy efficiency management to truly apply ship energy efficiency plans to daily operations. Thus, the improving parameters are "33: Convenience of use." However, helping employees learn requires training and teaching costs. Therefore, the worsening parameter is "19: Energy spent by moving object."

(3) Identification of the intentions of the innovative principles from the contradiction matrix: The innovation principles corresponding to the contradiction matrix are "Principle 19: Periodic action" and "Principle 35: Parameter change," and both are appropriate.

(4) Formulation of strategies according to innovative principles: "Principle 19: Periodic action" is defined as if the action has been cyclical, and the size or frequency of the period can be changed. Therefore, the proposed strategy (S4) is to implement energy efficiency management training courses of different frequencies and levels, so that crew members of different levels can clearly implement their own energy efficiency management requirements and strengthen their awareness of energy conservation and energy efficiency control. Through case studies, training courses can also well guide ordinary crew members to deal with actual operation management operations. "Principle 35: Parameter Change" means to change the temperature. Therefore, the proposed strategy (S5) is to implement a bonus incentive system to improve employees' awareness of green environmental protection and ensure that the energy efficiency management plan is implemented in the daily operation of ships. Therefore, the ship team with high energy efficiency and low energy consumption should be given incentives for promotion or salary increase to optimize ship operation management.

5) Ship energy consumption detection system (Q14)

(1) Description of the problem: At present, most shipping enterprises in China still adopt the manual recording of energy consumption and manual statistical analysis in terms of energy consumption monitoring and management. This method has shortcomings such as insufficient data analysis, high error rate, low timeliness, and inaccurate data records. Achieving scientific statistics on the actual energy consumption of ships needs further effort. In the absence of the effective realtime monitoring of ship energy consumption and data analysis results, providing shipping enterprise managers an accurate basis for decision making is thus difficult. In the context of increasingly tight energy supply and strong demand, the proportion of energy costs has gradually increased, requiring shipping enterprises to reduce operating costs and improve energy efficiency to achieve refined energy management.

(2) Definition of the improving and worsening parameters: The R\&D of a ship energy consumption monitoring system intelligently replaces the manual statistics of energy consumption data, which can help optimize the level of ship energy consumption management and improve the efficiency of ship operations. Therefore, the improving parameter is "28: Accuracy of measurement." However, using the ship energy consumption monitoring system to perform data statistics instead of manual copying operations can save part of the employment cost, but it may cause some employees to be laid off. Hence, the worsening parameter is "7: Volume of moving object."

(3) Identification of the intentions of the innovative principles from the contradiction matrix: The innovation principles corresponding to the contradiction matrix are "Principle 25: Self-service," "Principle 26: Copying," and "Principle 28: Mechanics substitution." Specifically, the appropriate innovation principles are "Principle 25: Self-service" and "Principle 26: Copying."

(4) Formulation of strategies according to innovative principles: "Principle 26: Copying" is defined as the use of a centralized electronic database instead of paper records that can help facilitate the simultaneous use by multiple people. Therefore, the proposed strategy (S6) is to establish an energy consumption intelligent monitoring platform system to replace manual data recording. This system can assist in achieving the refined management of energy consumption. "Principle 25: Self-service" is defined as making an object serve itself by performing auxiliary functions. Hence, the proposed strategy (S7) is to automatically analyze the energy consumption data generated during ship operations through the energy consumption data collected by the monitoring platform, which can quickly help shipping enterprises find energy consumption problems and explore energy-saving potentials. Improving energy conservation and optimizing production operation organization and process flow are thus helpful for shipping enterprises, thereby improving energy efficiency; reducing energy costs; and establishing refined, intelligent, and data-based energy management for shipping enterprises.

6) Energy saving and emission reduction (Q13)

(1) Description of the problem: China's shipping industry accounts for a large proportion of its energy consumption, but energy utilization efficiency is relatively low. Thus, the issue of energy saving and emission reduction of ships cannot be ignored. To promote the low-carbon and sustainable development of China's shipping industry, formulating goals, plans, and measures suitable for energy conservation and emission 
reduction is necessary. However, due to the relatively weak work foundation, the insufficient management mechanism, and the lack of awareness of energy conservation among crew members, all parties must make efforts to further improve and implement policies and regulations, safeguard measures, and system management.

(2) Definition of the improving and worsening parameters: To develop a low-carbon and sustainable development path for China's shipping industry, government departments should establish a long-term mechanism for energy conservation and emission reduction to regulate the daily operations of shipping enterprises. Therefore, the improving parameter is "10: Force." As energy-saving and emission reduction policies have become more stringent and regulated than before, shipping enterprises are also facing pressure to adapt to the new regulations to some extent while actively responding to the new policies. Hence, the worsening parameter is " 11 : Tension, pressure."

(3) Identification of the intentions of the innovative principles from the contradiction matrix: The innovation principles corresponding to the contradiction matrix are "Principle 36: Phase transition," "Principle 35: Parameter change," and "Principle 21: Skipping." Specifically, the appropriate innovation principle is "Principle 35: Parameter change."

(4) Formulation of strategies according to innovative principles: "Principle 35: Parameter change" means to change the temperature. Therefore, the proposed strategy (S8) suggests that while government departments should establish a long-term mechanism for energy conservation and emission reduction to regulate the daily operations of ship enterprises, they must also establish an incentive mechanism to encourage shipping enterprises to implement energysaving and emission reduction. Government departments can release project application information to attract shipping enterprises to apply for projects. Through the implementation of these projects, shipping enterprises can obtain subsidies for energy conservation and emission reduction, thereby convincing shipping enterprises to vigorously develop green ships and establish an energy-saving emission reduction mechanism to comply with standards and regulations. Shipping enterprises should strive to improve their own technical and management levels to adapt to the new standards and regulations, continuously improve their core competitiveness, and ensure that they are in a favorable position in the increasingly internationalized shipping market.

In summary, based on the contents of the six KSFs, eight green ship development strategies are proposed in this study.

\section{StRATEGIC PlanNing FOR THE DEVElOPMENT OF GREEN SHIPS}

According to the contents of the eight development strategies, the development of green ships should focus on "intelligent systems," "incentive systems," and "green devices." These eight strategies are divided into three stages on the basis of the length of time spent on their implementation and its degree of difficulty: short-, medium-, and long-term, as presented in Table 4. The "intelligent system," "incentive system," and "green device" strategies are then respectively integrated with the ships' life cycle, as depicted in Fig. 2, to enable shipping enterprises to develop green ships in a clear and orderly manner.

First, the green device strategies are S1 and S3. The green concept should be included in the early design phase of the ship life cycle, so that the subsequent ship life cycle can reduce environmental pollution during the realization of each phase. That is, the short-term strategy of green installations must use electronic databases to collect and store ship drawing information in the ship design stage (S1). The medium-term strategy of should design one or more standardized series of products corresponding to different green ship types in the ship design stage and use rapid or prototyping manufacturing (S1). The long-term strategy must develop new high-efficiency and energy-saving green ship powerplants (S3) in the ship design stage.

Second, the smart system strategies are S2, S6, and S7. After incorporating the green concept into the initial stage of the ship design phase, establishing a green system in the ship design phase and in the use phase is necessary. This system collects relevant ship operation index data to achieve the optimization of the parallel collaborative ship design process and monitor the environmental impact of energy consumption and emission pollution. Therefore, the shortterm strategy of intelligent systems should establish an IT service management system in the ship design stage to optimize the process of parallel collaborative design of ships (S2). The medium-term strategy must establish an energy consumption intelligent monitoring platform system (S6) in the ship design stage. The long-term strategy of intelligent systems should collect energy consumption data in the ship use stage, discover energy consumption problems, and explore the energy-saving potentials of ships (S7).

TABLE 4: Core CONTENT OF THE STRATEGY AT EACH DEVElopment STAGE

\begin{tabular}{llll}
\hline \hline $\begin{array}{l}\text { Core content } \\
\text { of strategy }\end{array}$ & \multicolumn{1}{c}{ Short-term } & \multicolumn{1}{c}{ Development stage } \\
\cline { 2 - 5 } Green device & $\begin{array}{l}\text { S1. Use electronic databases to collect and } \\
\text { store ship design drawing information }\end{array}$ & $\begin{array}{l}\text { S1. Design one or more standardized series } \\
\text { of products for different green ship types } \\
\text { and use rapid or prototyping manufacturing }\end{array}$ & $\begin{array}{l}\text { S3. Develop new, highly efficient, and } \\
\text { energy-saving green ship powerplant } \\
\text { equipment }\end{array}$ \\
Smart system & $\begin{array}{l}\text { S2. Establish an IT service management } \\
\text { system to optimize the parallel } \\
\text { collaborative design process of ships }\end{array}$ & $\begin{array}{l}\text { S6. Establish an energy consumption } \\
\text { intelligent monitoring platform system }\end{array}$ & $\begin{array}{l}\text { S7. Collect energy consumption data, } \\
\text { discover energy consumption problems, and } \\
\text { explore the energy-saving potentials of } \\
\text { ships }\end{array}$ \\
$\begin{array}{llll}\text { Incentive } \\
\text { system }\end{array}$ & $\begin{array}{l}\text { S4. Implement energy efficiency } \\
\text { management training courses of different } \\
\text { frequencies and levels }\end{array}$ & S5. Implement a bonus incentive system & $\begin{array}{l}\text { S8. Establish an incentive mechanism for } \\
\text { ships to implement energy conservation and } \\
\text { emission reduction funds }\end{array}$ \\
\hline \hline
\end{tabular}




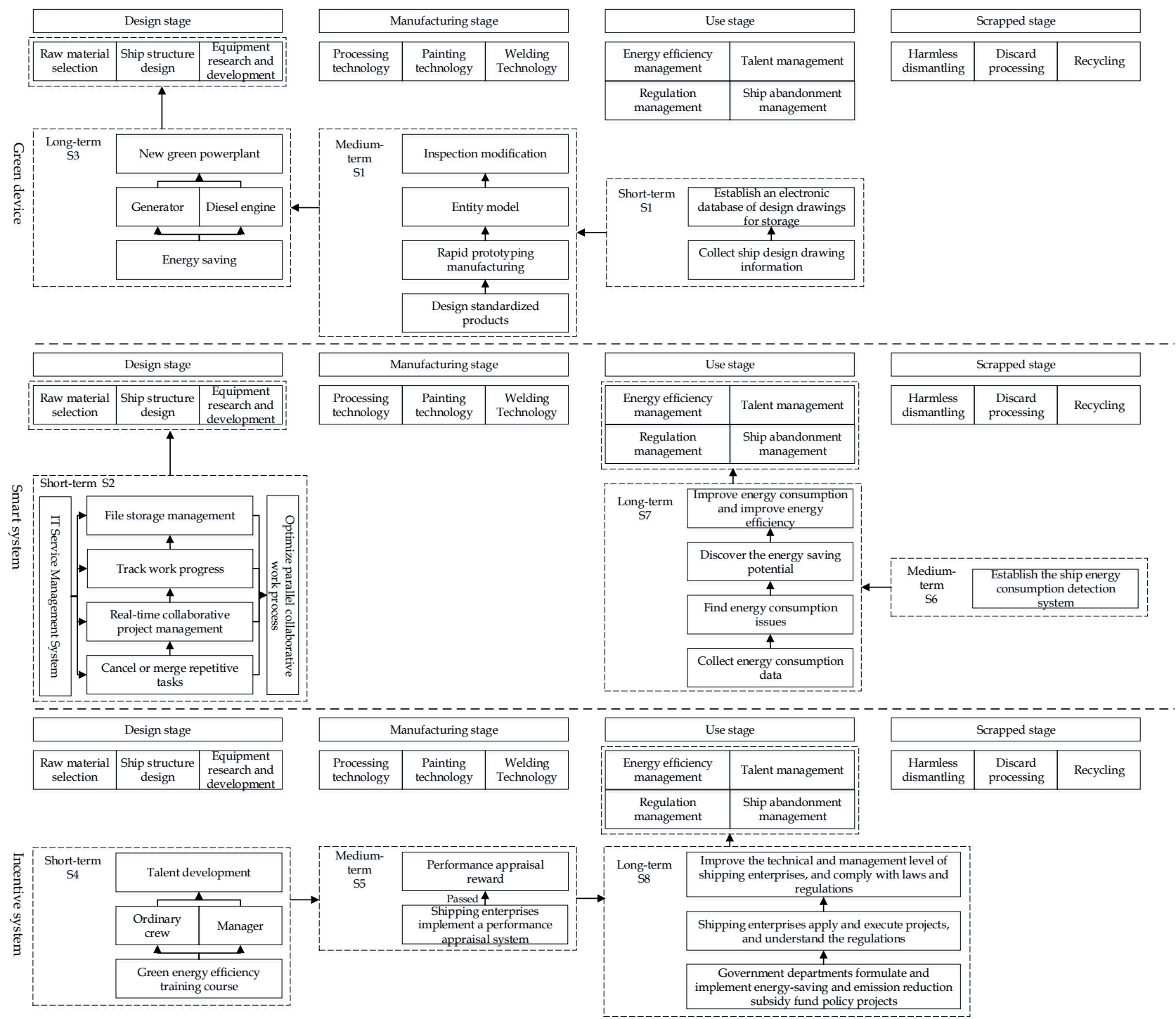

Fig. 2. Strategic planning and development of green ships.

Third, the incentive system strategies are S4, S5, and S8. After the smart system collects energy consumption data, the short-term strategy of incentive systems should implement energy efficiency management training courses of different frequencies and levels in the ship use stage (S4) for crew members to exhibit green ship performance and improve the efficiency of green ship execution. The medium-term strategy must conduct the performance appraisal of crew members in the manufacturing stage and implement a bonus incentive system for those who exhibit green ship performance (S5). The long-term strategy should establish the energy saving and emission reduction fund reward mechanism of ships in the ship use stage to improve the enthusiasm of ship enterprises to develop green ships (S8).

\section{CONCLUSION}

The environmental pollution caused by ships in operation has become the focus of the international community. The global shipping industry has introduced new policies and regulations on sulfur restrictions, and various environmental standards have become increasingly stringent. Under this situation, China should actively respond to the world's new rules and regulations and uphold the concept of sustainable development to promote the development and scientific management of green ships. Through the application of innovative green shipbuilding technologies, the need of international and domestic shipbuilding markets to enhance the international competitive position of China's shipping enterprises is met. The development of green ships can be accomplished not only by technological innovation but also through every link in the entire life cycle of their design, manufacture, operation, and dismantling. This study identifies six KSFs from the indicator factors affecting the entire life cycle of green ships. It also proposes eight strategies to provide them with limited resources to invest in key green ship indicators when developing green ships. The investigation is expected to help China's shipping enterprises increase their chances of successfully developing green ships and achieve the multiple goals of low pollution, low energy consumption, and multiple benefits to the greatest extent.

\section{ACKNOWLEDGMENT}

Part of this paper was supported by the School-level scientific research project of Beijing Institute of Technology, Zhuhai, under Contract XK-2018-17. 


\section{REFERENCES}

[1] Y. P. Yuan, "Research on the Development of China's Port Logistics and Foreign Trade," M.S. thesis, Dept. of International Economics and Trade, Nankai University, Tianjin, China, 2006.

[2] China brand, 2020 Global Top 20 Container Port Throughput Forecast, 2020. from http://www.tradeinvest.cn/information/6816/detail.

[3] Ministry of Ecology and Environment of the People's Republic of China, China Motor Vehicle Environmental Management Annual Report, Beijing: Ministry of Ecology and Environment of the People's Republic of China, 2018.

[4] M. Polakis, P. Zachariadis, and J. O. de Kat, The Energy Efficiency Design Index (EEDI), Switzerland: Springer, 2019.

[5] J. F. Rockart, "Chief Executives Define Their Own Data Needs," Harvard Business Review, vol. 57, no. 2, pp. 81-93, 1979.

[6] Y. T. Zhang, and B. Li, "An Empirical Study on the Critical Success Factors of Supplier Integration," Technoeconomics and Management Research, vol. 7, pp. 50-56, 2018.

[7] A. D. Aaker, Strategic Market Management, New York: John Wiley, 1984.

[8] C. T. Ren, "Research on Green Degree Evaluation System of Marine Powerplant," M.S. thesis, Dept. of Marine Engineering, Dalian Maritime University, Dalian, China, 2009.

[9] Z. Zeng, and L. X. Hu, "Research on Ship Drag Reduction Technology," Technology and Economic Guide, vol. 4, pp. 95-96, 2017.

[10] X. X. Zhang, F. Zhao, C. R. Wang, X. G. Zeng, and J. J. Zhao, "Research on the Development Strategy of Green Ship Technology," Engineering Science, vol. 18, no. 2, pp. 66-71, 2016.

[11] Q. Z. Ding, "Research on the Issues of Green Technology in the Ship Life Cycle," M.S. thesis, Dept. of Design and Manufacture of Ships and Marine Structures, Harbin Engineering University, Harbin, China, 2011.

[12] J. K. Mao, "Discussion on Green Shipbuilding Technology," China Water Transport, vol. 8, no. 5, pp. 6-8+10, 2008.

[13] X. X. Wang, and L. Zhu, "Energy Efficiency and Environmental Protection and Green Shipbuilding," Marine Technology, vol. 3, pp. 5-7, 2012.

[14] Y. D. Liu, and S. J. Su, "Collaborative Environment and Key Techniques of Ship Integrated Framework Design," Journal of Dalian Maritime University, vol. 37, no. 1, pp. 25-28+31, 2011.

[15] T. N. Jia, "Research on the Influence of Lightweight Structure on the Energy Efficiency Design Index," M.S. thesis, Dept. of Naval Architecture and Ocean Engineering, Dalian Maritime University, Dalian, China, 2016.

[16] Z. Q. Wu, "The Concept of Green Ship and the Development of Ship Dynamic Technology," Journal of Wuhan Technical College of Communications, vol. 12, no. 3, pp. 25-28, 2010.

[17] C. Q. Yuan, Y. Zhang, X. Q. Bai, Y. W. Sun, and X. P. Yan, "Synergistic Effect of Non-carbon Energy and Energy Efficiency Improvement in Ship," Ship Engineering, vol. 35, no. 6, pp. 116-119, 2013.

[18] J. F. Hao, Z. X. Qiang, J. L. Shi, S. W. Suo, and L. N. Xiao, "Research on Response Measures for Ship Emission Reduction and Energy Saving," Ship Science and Technology, vol. 34, no. 9, pp. 3$10,2012$.

[19] Y. L. Shang, "Standardization Requirements and Development Countermeasures for Energy Saving and Emission Reduction," International Proceedings of 12th Annual Meeting of China Association for Science and Technology, pp. 1-5, 2010.

[20] X. X. Wei, "The Research and Development of Energy Consumption Monitor Online System for Vessel," M.S. thesis, Dept. of Naval Architecture and Ocean Engineering, Jimei University, Xiamen, China, 2016.

[21] J. L. Wang, X. F. Gu, and X. C. Yin, "Research and Application of Online Energy Consumption Monitoring System of Harbor Boat," Port Operation, vol. 4, pp. 30-32, 2015.

[22] S. J. Yu, "Current Development and Future Direction of the Green Ship," Ship Boat, vol. 21, no. 4, pp. 1-5, 2010.

[23] Y. Gao, "The Future Direction of Green Ships," China Ship Survey, vol. 12, pp. 48-51+113, 2011.

[24] Eworldship.com, Green ship, 2014. Retrieved from http://www.eworldship.com/index.php?m=wiki\&c=index\&a=doc_det ail\&did=3982.

[25] Y. M. Jiang, M. H. Zhu, and D. C. Zheng, "Progress in Research on Treatment Technology of Shipping Sewage," Journal of Ningbo University (Natural Science and Engineering Edition), vol. 24, no. 4, pp. 128-132, 2011.
[26] J. Xu, and T. Liu, "Recycling and Utilization of Hazardous Waste in Shipbuilding Industry," Inner Mongolia Environmental Sciences, vol. 27, no. 6, pp. 74-76, 2015.

[27] S. N. Zheng, "The Development of the Shipbuilding Industry Environment Protection Legal System," M.S. thesis, Department of Law, Harbin Engineering University, Harbin, China, 2013.

[28] L. Zhu,'Analysis on Energy Saving and Emission Reduction of Clean Energy Technology in Ports-container Terminal for Example,' Energy Conservation \& Environmental Protection in Transportation, vol. 13, no. 5, pp. 34-36, 2017.

[29] J. L. Deng, "A novel GM(1,1) Model for Non-equigap Series," The Journal of Grey System, vol. 9, no. 2, pp. 111- 116, 1977.

[30] D. R. Daniel, "Management Information Crisis," Harvard Business Review, vol. 39, pp. 111-116, 1961

[31] C. K. Kao, and A. P. Chen, "Service Blueprint Development for China's College Campus Express Delivery based on Grey Relational Analysis and TRIZ," Journal of China Studies, vol. 21, no. 4, pp. 217 $247,2018$.

[32] S. D. Savransky, Engineering of Creativity: Introduction to TRIZ Methodology of Inventive Problem Solving, FL: CRC Press, 2002.

[33] D. Z. Bian, C. P. Hu, Z. Yang, M. Wang, W. J. Shan, and F. F. Song, "Research on Application of Unified Database Integration Platform to Shipbuilding Enterprises.," Ship Science and Technology, vol. 42, no. 7, pp. 134-138, 2020.

[34] Q. C. Song, "Research and Development of Ship Parallel Collaborative Design Application Technology," M.S. thesis, Dept. of Naval Architecture and Ocean Engineering, Dalian Maritime University, Dalian, China, 2011.

[35] T. B. Zhao, X. J. Zhou, A. H. Qiu, F. Z. Guo, and X. Y. Zeng, "Technology and Application of New Highly Efficient Ship Dieselelectric Hybrid System," International Proceedings of 17th Annual Meeting of the China Association for Science and Technology, pp. 1-6.

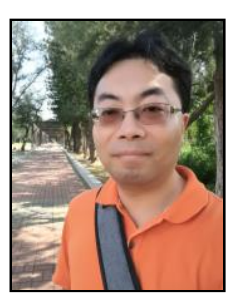

Ching-Kuei Kao is an associate professor in the Department of Logistics Management at Fujian University of Technology and the director of the LNG Industry Chain Research Center of the Fujian University of Technology. He received a $\mathrm{Ph} . \mathrm{D}$. in the Industrial Engineering and Management from National Chiao-Tung University in Taiwan. His research interests include production planning and scheduling, green port shipping logistics, and logistics strategy planning.

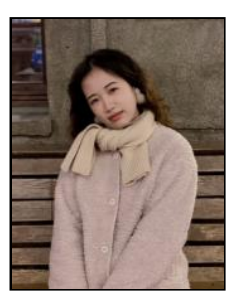

Qi-Qi Chen graduated from the Department of Logistics Management of Beijing Institute of Technology, Zhuhai in 2019. Her areas of interest are warehouse management, supply chain management, and green port shipping logistics.

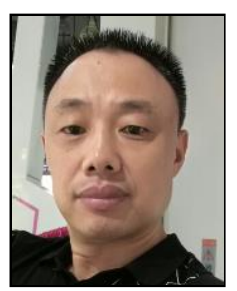

Yang Zhong is an associate professor in the Department of Logistics Management at Beijing Institute of Technology, Zhuhai (ZHBIT). He has more than 10 years of teaching experience in ZHBIT and has a wide experience in teaching Logistics related courses. His research interests are in the area of emergency logistics and port and shipping logistics.

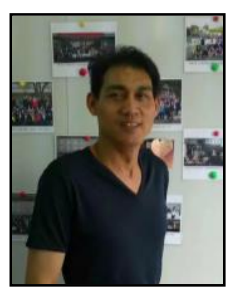

Peng-Jung Lin is the professor in the Department of Business Administration at Fujian University of Technology. He received a Ph.D. in the Business from National Chi-Nan University in Taiwan. His main research interests include strategic management, resource-based view, organizational learning theory. $\mathrm{He}$ has presided over and participated in the completion of 33 research projects, including ministerial-level research projects, provincial-level research projects, municipal-level research projects, school-level research projects, innovation and entrepreneurship projects. Moreover, he has published more than 60 research papers in reputed journals and co-authored five monographs, and has held four patents. 